\title{
Pulse Electroplating of Ultra-Fine Grained Zinc Coating on 316L Stainless Steel and its Corrosion Behaviour
}

\author{
Yu Tan, Yunfei Xu, Hao Zhang, Chenhao Sun, Kexin Liang ${ }^{*}$, Shenghan Zhang
}

Department of Environment Science and Engineering, North China Electric Power University, No.689, Yonghua North Road, Baoding, Hebei Province, 071000, P.R.China

*E-mail: kexin91802@163.com

doi: $10.20964 / 2019.01 .66$

Received: 3 May 2018 / Accepted: 7 November 2018 / Published: 10 May 2019

Pulse electrodeposition (PED) was used to produce nanocrystalline zinc film from zinc sulphate electrolyte. Differences reductive/oxide voltage were employed to study the grain size and surface morphology of these ultra-fine zinc coating with SEM. Also pulse times were discussed for the same electricity. The corrosion behaviour of these as formed zinc coating are investigated by potentiodynamic polarization. The different corrosion resistances of SS316L under different applied voltages and pulse time conditions are summarized, providing a foundation for further consideration of electroplating zinc.

Keywords: pulse voltage; electroplating zinc; zinc coating; corrosion behaviour

\section{FULL TEXT}

(C) 2019 The Authors. Published by ESG (www.electrochemsci.org). This article is an open access article distributed under the terms and conditions of the Creative Commons Attribution license (http://creativecommons.org/licenses/by/4.0/). 